\title{
Adapting brief Behavioural Activation (BA) for adolescent depression: a case example
}

Article

Accepted Version

Pass, L., Brisco, G. and Reynolds, S. (2015) Adapting brief Behavioural Activation (BA) for adolescent depression: a case example. The Cognitive Behaviour Therapist, 8. e17. ISSN 1754-470X doi: https://doi.org/10.1017/S1754470X15000446 Available at https://centaur.reading.ac.uk/46298/

It is advisable to refer to the publisher's version if you intend to cite from the work. See Guidance on citing.

Published version at: http://dx.doi.org/10.1017/S1754470X15000446

To link to this article DOI: http://dx.doi.org/10.1017/S1754470X15000446

Publisher: Cambridge University Press

All outputs in CentAUR are protected by Intellectual Property Rights law, including copyright law. Copyright and IPR is retained by the creators or other copyright holders. Terms and conditions for use of this material are defined in the End User Agreement.

www.reading.ac.uk/centaur

\section{CentAUR}


Central Archive at the University of Reading

Reading's research outputs online 


\title{
Adapting brief Behavioural Activation (BA) for adolescent depression: A case example
}

\author{
Laura Pass ${ }^{\mathrm{a}}$, Gemma Brisco ${ }^{\mathrm{a}}$ and Shirley Reynolds ${ }^{\mathrm{a}}$
}

Affiliation: ${ }^{\mathrm{a} C h a r l i e}$ Waller Institute, School of Psychology and Clinical Language Sciences, University of Reading, UK

\begin{abstract}
There is an increasing evidence base for the effectiveness of Behavioural Activation in treating adult depression, however there has been little investigation of using this approach with adolescents. This article reports on the adaptation of brief Behavioural Activation for Depression (BATD) for adolescents (BATD-A). A case study is reported to illustrate the brief structured approach, treatment response as indicated by routine outcome measures, and the family's view of the intervention. The adaptations made to the adult BATD manual are discussed including parental input, adapted values and activities, and engagement issues. It is hoped that following further evaluation, BATD-A could be successfully delivered as a low-intensity intervention for depression.
\end{abstract}

Key words: Depression, children and adolescents, behavioural therapy, young people.

\section{Learning objectives:}

1) To review the key principles of brief BA for depression

2) To consider some developmental and contextual issues that might be important when adapting BA for adolescents

3) To illustrate how adolescent-identified values and value-based activity in BA were useful for this particular case

4) To evaluate the use of brief BA with an adolescent in the context of a single case study

\section{Introduction}

Depressive symptoms are common among adolescents (Thapar et al., 2012), with epidemiological studies in the US and UK suggesting up to $20 \%$ of adolescents will experience an episode of depression by the time they reach 18 years old (e.g. Lewinsohn, Rohde, \& Seeley, 1998). A metaanalysis of worldwide prevalence of depression in young people suggests around $2.6 \%$ of the population experience a depressive disorder at any one time (Polanczyk et al., 2015). Depression during adolescence can have lifelong negative impacts; adolescents who experience depression are 
more likely to relapse as adults (Dunn \& Goodyer, 2006), and to develop other long term mental health difficulties including personality disorders and substance abuse (Rudolph \& Klein, 2009).

Cognitive Behavioural Therapy (CBT) is a well validated treatment for adults with depression (NICE, 2009). NICE guidelines for the treatment of depression in children and adolescents also recommend CBT, along with interpersonal therapy (IPT) psychodynamic psychotherapy and family therapy (NICE, 2015). However access to these therapies (and therapists) can be severely limited (e.g. Stallard et al., 2007). Brief psychological approaches, which might be delivered by a range of practitioners, are a possible method of improving access to talking therapies for adolescents.

The effectiveness of CBT for depressed adolescents also seems to be, at best, moderate. In a metaanalysis of psychotherapy for depression in children and adolescents, Weisz and colleagues (2006) found that psychological treatments with a cognitive component were not more effective than treatment that did not include cognitive components. They suggested that treating depression in young people may not require attention to dysfunctional cognitions.

Behavioural theory suggests that reinforcement of depressive behaviours, and lack of reinforcement of non-depressed behaviour, maintains low mood. Behavioural Activation (BA; Martell et al., 2001) is a psychological therapy typically involving 20-24 sessions, and is included in the NICE guidelines for treatment of depression in adults (NICE, 2009). There are plausible reasons to consider BA as a promising treatment for adolescents. Firstly, cognitively based therapy may be challenging for many depressed teenagers for whom cognitive development is on-going. BA does not require cognitive intervention. It is also simple to explain, simple to understand and reasonably straightforward to incorporate into an adolescent's life. A small number of case series implementing BA with adolescents (involving up to 22 sessions) have reported promising results, although few participants complete all sessions (e.g. McCauley et al., 2011; Ritschel et al., 2011). One randomised controlled trial has recently reported on the success of a 14-session Adolescent Behavioral Activation Program (A-BAP), adapted from the Martell BA approach (McCauley et al., 2015). In this study, A-BAP ( $n=$ 35) was found to be as effective as evidence based practice for depression (CBT or IPT, $n=25$ ), with significant decreases in depression symptoms in both groups.

A brief form of BA has also been developed; Behavioural Activation for the Treatment of Depression (BATD; Lejuez et al., 2001; BATD-R: Lejuez et al., 2011). This is a-manualised programme of 5 -10 sessions. The key aim is to increase activity and exposure to positive reinforcement, while also decreasing reinforcement for depressive behaviour. Four key concepts are used: 1) Consideration of key life areas; 2) Identification of values in each life area, 3) Selection and daily engagement in valued activities, 4) Structure and support available to live a valued life. Adapted versions of BA are widely used in the UK Increasing Access to Psychological Therapies (IAPT) programme as part of a stepped care approach (Clark, 2011). 
There is little evidence to show if brief BA is effective with adolescents, although preliminary reports suggest that it holds promise (e.g. Ruggiero et al., 2005). Given the UK context of limited resources in child and adolescent mental health services and associated difficulties in accessing psychological therapy, there is a good rationale to examine treatment outcome using BATD which requires fewer treatment sessions. The aim of this paper is to describe the use of BATD, adapted for adolescents, and to evaluate it in a single case study with a depressed teenager referred to routine Child and Adolescent Mental Health services (CAMHS) in the UK.

\section{Brief BA for Adolescents (BATD-A)}

We adapted Brief BA for adolescents with depression with input from the BATD team (Lejuez, personal communication). The adapted treatment includes all key content from the adult BATD manual (Lejuez et al., 2011). Treatment is delivered using a manual, shared by the therapist and adolescent in eight one-hour sessions, and a 30 minute review session one month later.

Although the key elements of Brief BA are included in BATD-A a number of changes were made to make the material relevant and engaging to adolescents. These were:

- New manual for adolescents designed to be interactive, collaborative and age appropriate

- Inclusion of psycho-education, including adolescent development

- Two case studies to make the material more engaging

- Inclusion of parents in treatment

- A manual specifically for parents

- Addition of problem solving as a technique

The manual was developed with input from adolescents to refine the layout, content and formatting. The manual includes a chapter for each treatment session; this is completed by the young person and therapist together. Two case studies are used throughout the manual. These illustrate a young person with low levels of activity, and one where the young person continues to engage in activities but experiences little positive reinforcement. These cases are followed throughout the manual to illustrate BATD-A concepts (e.g. activity logs, contracting) and how a BA approach might differ for individual adolescents. The key concept of Life Area was adapted to be more relevant to young people. with Three broad areas are highlighted of 'Me' (hobbies/fun, physical health, looking after myself), 'Things that matter' (education/work, everyday stuff, the bigger picture), and 'The people that matter' (family, friends, boyfriend/girlfriend). Adult focused life areas were removed or minimised.

A key issue that required adaptation of BATD was the fact that adolescents are not yet autonomous, independent individuals. Most of their day-to-day life requires involvement (and authorisation) from parents. Parents are often the providers of positive reinforcement or tangible reinforcers (e.g. money) 
and it is therefore essential to engage them in treatment where possible. At the same time the adolescents' need for autonomy and independence is developmentally important and BATD-A therefore aims to balance parental involvement and adolescent developing autonomy. To do this, BATD-A ([Authors] et al., 2014) routinely involves parents or carers in treatment and important adults are consulted to help identify goals and valued activities.

Across the delivery of 8 sessions of BATD-A parents are invited to join sessions 1, 6 and 8. Parental input is limited within sessions to ensure the young person is kept at the centre of treatment, and to facilitate a good therapeutic alliance. In addition a specific manual for parents provides psychoeducation, aims to help them understand the rationale of treatment, and supports then to help their child outside sessions. Contracts are a tool from adult BATD that is used in BATD-A to help parents and adolescents negotiate the parental role. This technique involves adolescents being asked to recruit help for specific tasks from important others around them, including parents (e.g. a lift to football club).

A typical area where discussion and negotiation is needed between parent(s) and child is over finding a 'balance' between activities related to Achievement, Closeness to others, and Enjoyment (ACE; Vivyan, 2014). Adolescents and parents often do not agree about what activities are most important. In BATD-A the emphasis is placed on the young person's values and identifying what is important to them rather than to others, while problem-solving any barriers. This led to the inclusion of problemsolving as an optional section in the BATD-A manual, to help negotiate differences between parents and adolescents. Additionally, problem solving skills are helpful for adolescents who are still developing their executive functioning abilities or for whom executive functioning is impaired because of their depression.

\section{Case background and presenting problems}

\section{Selection of case}

The case described below was chosen to illustrate a relatively straightforward application of the BATD-A approach, with a young person who was being seen within the local Child and Adolescent Mental Health Service (CAMHS), in the Anxiety \& Depression (A\&D) care pathway. This pathway offers assessment and intervention for young people for whom anxiety and/or depression is their main presenting difficulty. More complex presentations or those requiring multi-agency working (e.g. looked after children) are seen in the Specialist CAMHS pathway.

This case was selected from an open case series that is currently being collected for a pilot evaluation of BATD-A in the A\&D CAMHS pathway. She was receiving routine care from the pathway due to ongoing functional impairment from her low mood (most notably reduced school engagement), and 
was reviewed by the pathway Child Psychiatrist regularly regarding her anti-depressant medication. She had previously received CBT and did not find it helpful. BATD-A was therefore considered as an alternative treatment, and this young person was one of the first in the case series to complete BATDA treatment.

Case background

'Fiona' (a pseudonym) was a 15 year old girl with symptoms of low mood. She attended an initial assessment in the local CAMHS. This identified predisposing vulnerabilities (e.g. paternal history of depression) and negative life events (school exams, increase in academic pressure) which may have precipitated the onset of low mood. Fiona reported a stable, positive relationship with her family (mother, father, younger brother), especially her mother. Fiona's father had a history of recurrent depression with his last episode about 5 years previously.

Fiona presented with mild depression (low mood, cognitive difficulties, anhedonia and fatigue). Her symptoms had started six months previously, at a time when she was preparing for public examinations. She had been assessed by a private child and adolescent psychiatrist, prescribed Fluoxetine, and received seven sessions of CBT with a private therapist. At the time of referral she was still taking Fluoxetine. She reported persistent low mood and declined further CBT but was willing to try Brief BA. Medication management and review continued under the care of a CAMHS A\&D pathway Psychiatrist during BATD-A treatment.

\section{Measures}

Routine outcome measures and a specific BA measure were collected. These were:

Revised Child Anxiety and Depression Scale (RCADS; Chorpita et al., 2000)

The RCADS, and associated parent version (RCADS-P) are both 47-item questionnaires that assess anxiety and low mood in young people aged 8-18 years. The full RCADS and RCADS-P were completed at initial assessment, and at session 8. The self and parent-report RCADS depression subscales were completed immediately before every BA session.

Outcome Rating Scale (ORS; Miller \& Duncan, 2000)

On the ORS clients (and parents) are asked to rate, on a $10 \mathrm{~cm}$ line, the young person's functioning in four key areas: Individual, Interpersonal, Social and Overall. The scores for each area are summed to create a total functioning score. The ORS was completed before every BA session by Fiona and her mother.

Session Rating Scale (SRS; Duncan et al., 2003) 
The SRS is a four-item scale designed to measure the therapeutic relationship in four areas: Relationship, Goals and Topics, Approach or Method, and Overall Alliance. The SRS was completed after each session by Fiona.

Behavior Activation for Depression Scale-Short Form (BADS-SF; Manos, Kanter, \& Luo, 2011)

The BADS-SF consists of nine items providing a total activation score. The BADS-SF form is not currently validated for adolescents and is not a routine outcome measure, however it was used as a clinical tool to explore behavioural change.

At initial assessment, Fiona scored just below the clinical threshold for depressive symptoms on the RCADS depression subscale. Her anxiety symptoms were relatively low, except for separation anxiety; however on closer inspection this scale appeared inflated by Fiona's trouble going to school and worrying in bed at night, which was related to school concerns. At assessment Fiona's mother rated her depression at a clinically significant level and her anxiety symptoms below threshold (including separation anxiety). Fiona was not experiencing suicidal ideation and had never selfharmed.

\section{Conceptualisation}

With Brief BA for Adolescent Depression delivered in CAMHs two different levels of case conceptualisation are used. The first is based on information gathered at the initial assessment. It is based on background information, (e.g. demographics, family composition, major life events), a timeline of symptoms and an overview of current symptoms. This provisional formulation can be used in supervision of BATD-A where needed, to consider possible barriers to engagement or progress (e.g. unintentional reinforcement of an adolescent's depressive behaviour by family members, life events which may have reduced the opportunity for positive reinforcement for nondepressed behaviours).

For the majority of BATD-A cases advanced formulation skills are not required. Within BATD-A a behavioural maintenance cycle is used to understand, explain and tackle the young person's difficulties with mood. This cycle has three components (see Figure 1) and focuses on way in which the absence of reinforcement maintains depression and inactivity. This behavioural maintenance cycle was discussed with-Fiona and her mother in session 1. The family identified with this model and were able to elaborate the cycle by identifying that Fiona could not identify activities to engage in when she felt low.

[Figure 1 here]

\section{Treatment Goals}


In the first BA session, Fiona set three goals: "To feel I can cope", "To be able to do homework" and "Not get distressed by homework". She felt that she was currently $3 / 10$ towards achieving each of these goals.

\section{Course of BATD-A}

BATD-A follows a structured approach, (see Table 1). The structure is flexible in that session content can be moved earlier or later in sessions.

Table 1. BATD-A session overview

\begin{tabular}{|c|c|c|c|}
\hline $\begin{array}{l}\text { Session } \\
\text { number }\end{array}$ & Young person session content & Parent session content & Homework \\
\hline 1 & $\begin{array}{l}\text { Introduce BATD-A approach and } \\
\text { rationale, session workbook. }\end{array}$ & $\begin{array}{l}\text { Parent attends part of session } \\
\text { (rationale and structure of } \\
\text { BATD-A), parent workbook. }\end{array}$ & Activity log \\
\hline 2 & $\begin{array}{l}\text { Review BATD-A approach, review } \\
\text { activity log from previous week, sessio } \\
\text { workbook. }\end{array}$ & Parent workbook & Activity log \\
\hline 3 & $\begin{array}{l}\text { Review activity log from the previous } \\
\text { week, explore young person's values, } \\
\text { session workbook. }\end{array}$ & Parent workbook & $\begin{array}{l}\text { Activity log, } \\
\text { Values }\end{array}$ \\
\hline $4-5$ & $\begin{array}{l}\text { Review values, plan valued activities } \\
\text { across different life areas, session } \\
\text { workbook. }\end{array}$ & Parent workbook & $\begin{array}{l}\text { Valued } \\
\text { activities }\end{array}$ \\
\hline 6 & $\begin{array}{l}\text { Review progress, problem-solving and } \\
\text { contracting (if appropriate), session } \\
\text { workbook. }\end{array}$ & $\begin{array}{l}\text { Parent attends part of session } \\
\text { (review, problem-solving and } \\
\text { contracts), parent workbook. }\end{array}$ & $\begin{array}{l}\text { Valued } \\
\text { activities }\end{array}$ \\
\hline 7 & $\begin{array}{l}\text { Review progress, identify activities to } \\
\text { continue working towards, session } \\
\text { workbook. }\end{array}$ & Parent workbook & $\begin{array}{l}\text { Valued } \\
\text { activities }\end{array}$ \\
\hline 8 & $\begin{array}{l}\text { Review progress, relapse prevention, } \\
\text { session workbook and relapse } \\
\text { prevention handout. }\end{array}$ & $\begin{array}{l}\text { Parent attends part of session } \\
\text { (review, relapse prevention), } \\
\text { parent workbook. }\end{array}$ & \\
\hline Review & $\begin{array}{l}\text { Review progress, plan for further } \\
\text { input/discharge. }\end{array}$ & Parent attends part of review & \\
\hline
\end{tabular}


Fiona completed all eight sessions of BATD-A over nine weeks. She continued to take antidepressant medication throughout BA sessions and afterwards.

\section{Key themes during therapy}

1. Engagement with the model and therapist

Fiona was initially reluctant to engage in psychological work. She said that her previous experience of therapy (CBT) had not been positive. She described the therapist "drawing links between things that don't exist", such as suggesting that Fiona did not think she was good enough. Fiona was adamant that "I do think I'm good enough", and that the main issue was that she had to do things she felt were pointless (e.g. homework). Because 'homework' was so negative to her, a clear distinction was made by the therapist between school homework and therapy 'homework'.

At the start of session 2, Fiona's mother reported that she was refusing to get out of the car because she did not feel well. Session 2 took place in Fiona's mother's car. Fiona and the therapist wished to reviewed the detailed activity log she had completed. Fiona attended session 3 and all further scheduled sessions. In session 3 she did not identify any aspects of BATD-A or the therapist's style as barriers to engagement. The SRS was used to prompt these discussions, and showed that the therapeutic alliance improved across sessions (from 28.8 in session 1 to 37.1 in session 8).

2. Identifying values

Fiona was very clear that although other people thought school was important, she did not agree. She also stated that homework was not important to her, as it was often repeated material that had been covered in lessons. She frequently did not complete her homework and was then allowed to complete it later, during a detention. Fiona identified that her education value was "Passing GCSEs", but that this did not necessarily mean doing homework. This was a critical distinction for Fiona but not necessarily one shared by her parents or teachers.

Fiona also identified a key value, her love of all things German. She related this to the 'bigger picture' value, but also described how this was also a hobby, and linked to her career goal of wanting to work in Germany. Fiona expressed frustration at not being able to move to Germany immediately. This frustration appeared to be a barrier to her engaging in more achievable activities that still related to this value. However, with some problem-solving in sessions and concrete examples of how a variety of smaller, feasible activities can still enable an individual to live according to their values (and as a consequence be more likely to experience positive reinforcement), she began to consider alternative ways to work towards this value. More achievable activities Fiona identified included reading German books, watching German films, translating into German, and going to Germany on holiday. Understanding how aspirational values can be translated into a (potentially unlimited) number of 
specific and practical activities was a significant step for Fiona. This is emphasised in BATD-A, to empower adolescents to make behavioural changes despite their often limited autonomy.

\section{Involving parent(s)}

Fiona's mother was very supportive of the BATD-A work. Using the manual and her attendance at sessions 1, 6 and 8 she supported out of session 'homework' and behavioural change. Fiona did not always view her mother's suggestions as useful but she did acknowledge the benefit of her mother's practical and emotional support (e.g. her mother providing lifts, reminders of activity suggestions Fiona had previously made). Fiona and her mother also used contracts in increase reinforcing activities and used sessions 6 and 8 to discuss Fiona's values. Fiona's father did not attend sessions and was described as having a less close relationship with Fiona. However, Fiona identified her father as providing useful financial resources.

\section{Outcome}

Outcome was reviewed one month after session 8 with Fiona and her mother. Fiona and her mother's routine outcome measures indicated that after starting BA, Fiona's depression symptom scores reduced, and her functioning scores increased as well as her behavioural activation (see figure 1). Fiona and her mother explained that their ratings on the ORS were relatively low because they viewed that a high score would reflect a 'one-off', event (e.g. the joy at winning an intensely desired prize, going on a holiday of a lifetime) rather than feeling this way daily. Both were satisfied with Fiona's current level of functioning.

At the review Fiona was attending school regularly. She reported making significant progress towards her goals; doing homework was rated as 5/10, coping was rated $9 / 10$ and not feeling distressed by homework was 10/10. Fiona's mother reported that she would prefer Fiona to be completing slightly more homework, but agreed that this did not seem to be negatively affecting her academic performance

[Figure 2 here]

There was reliable improvement on the RCADS depression subscale for self-report and maternal report, and on Fiona's ORS scores, all of which were in the non-clinical range at the end of treatment. Fiona's mother's report on the ORS suggested Fiona had made reliable improvement in her functioning, but was still below the cut-off for a non-clinical population (28). This reflected her mother's concern over a few recent (brief) periods of low mood, which Fiona was adamant felt-were normal for any teenager and did not accurately reflect her current level of functioning. Risk had remained low throughout sessions, with no self-harm or suicidal ideation reported. The BADS-SF scores also indicated increased behavioural activation (from 28 at session 1 to 46 at the final session). 
While this measure is not currently validated for adolescents, it supported the verbal report from Fiona and her mother that there had been significant changes in her behaviour.

Fiona and her mother also gave feedback about their experience of BATD-A. Fiona stated that the aspect she liked best about BATD-A was that "it's more practical than CBT; it's applicable to reallife". She rated 'liking' BA (range: Really liked it- Hated it), and that it was 'Very' useful (range: Very-not at all). Fiona's mother also rated that she 'liked' the BA approach, and found it 'Very' useful. The aspects she liked the best were the "practical approach, flexible application". Both Fiona and her mother were happy to be discharged from Psychology. Fiona continued to be take Fluoxetine and to be monitored by the Child Psychiatrist as recommended by NICE (2015).

\section{Discussion}

This case study illustrates the use of BATD with a young person with residual depression and previous negative experience of CBT. It also highlights adaptations made from the adult BATD manual to make it suitable for adolescents.

BATD-A involves applying the basic principles of reinforcement and avoidance, but no detailed behavioural formulation or functional analysis is required. By focusing on the basic behavioural maintenance cycle (low mood, behavioural withdrawal and reduction of activities, reduced positive reinforcement), young people seem to engage well with the model. This case illustrates how the exploration and identification of personal values can be successful. The concept of considering the young person's own values, rather than those imposed on them by others (e.g. parents, teachers, peers), has been taken up with enthusiasm by every adolescent we have treated so far. Although it can be difficult to maintain a balance between parental and adolescent wishes and expectations, the explicit consideration of the adolescent's values appears to be developmentally appropriate, motivating, and meaningful to young people.

Although individuation and personal autonomy are key constructs during adolescence, therapy is provided in the context of an environment in which young people do not yet have autonomy. Engaging parental support, where possible, is important. BATD-A acknowledges and encourages parental involvement; whilst at the same time promotes the young person's autonomy and individuality. Many clinicians struggle to find the appropriate balance of individual and parentsupported therapeutic input with young people. Providing clear information about BATD-A and what happens in each session, including parents in some (but not all sessions), normalising differences between parents and children, and using problem solving to negotiate these appears to help most parents to feel involved without compromising the alliance between the young person and therapist. 
BATD-A is unlikely to be suitable for all teenagers with depressive disorders. Those less likely to be suitable for BATD-A include those with significant relational or family difficulties, or young people whose negative cognitions appear central to their depression. Although further research is needed to evaluate this, it is likely that clients who are in a state of acute crisis, or those who have emotion regulation difficulties (so present with very fluctuating mood), may struggle to engage with BATD-A. There is a degree of commitment to monitoring and scheduling activities between sessions that may not be possible for young people with very challenging home environments.

Young people who may be more likely to benefit from BATD-A llie include those with anhedonia as a core symptom, young people who struggle to access cognitions, those who have expressed a preference for non-cognitive work, or those who have failed to benefit from CBT. BATD-A may be an appropriate low intensity intervention for young people who have depressive symptoms, but do not meet criteria for CAMHS. While there are major differences between current adult and youth mental health services (and as noted, developmental and contextual issues that mean direct translation of approaches is not valid), it is possible that BATD-A could be implemented in a style similar to BA provided by Psychological Wellbeing Practitioners in adult IAPT services (Clark, 2011). The effectiveness of BATD-A with moderate to severe depression should also be investigated given the positive findings with adult depression (Ekers, Richards \& Gilbody, 2008), and therefore it may be useful to brief BA within the context of a stepped care model.

One particular challenge for BATD with adolescents is the lack of validated measures to capture the mechanism of change. The short version of the BADS was used in the case example to provide some BA relevant information, however there is a need for this and similar measures to be assessed for their psychometric properties when used with an adolescent population.

\section{Conclusion}

Brief BA for adolescent depression (BATD-A) is a promising treatment approach. It is important to conduct further single case studies and open trials to assess effectiveness.

\section{Summary}

This article presents a case study of BATD-A with a 15 year old girl, presenting with residual depression symptoms that had not remitted following medication and CBT. The discussion focuses on the largely positive outcomes, and how BATD-A may be a practical, acceptable therapy with other depressed adolescents and their families.

\section{Suggested follow-up reading}


Lejuez, C. W., Hopko, D. R., Acierno, R., Daughters, S. B., \& Pagoto, S. L. (2011). Ten Year Revision of the Brief Behavioral Activation Treatment for Depression (BATD): Revised Treatment Manual (BATD-R). Behavior Modification, 35, 111-161. doi: 10.1177/0145445510390929.

\section{Declarations of interest: None.}

\section{References}

Chorpita, B. F., Yim, L., Moffitt, C., Umemoto, L. A., \& Francis, S. E. (2000). Assessment of symptoms of DSM-IV anxiety and depression in children: a revised child anxiety and depression scale. Behaviour Research and Therapy, 38, 835-855. doi: 10.1016/S0005-7967(99)00130-8.

Clark, D. (2011). Implementing NICE guidelines for the psychological treatment of depression and anxiety disorders: The IAPT experience. International Review of Psychiatry, 23, 375-384.

Duncan, B. L., Miller, S. D., Sparks, J., Claud, D., Reynolds, L., Brown, J., \& Johnson, L. (2003). The Session Rating Scale: Preliminary psychometric properties of a "working” alliance measure. Journal of Brief Therapy, 3, 3-12.

Dunn, V., \& Goodyer, I. M. (2006). Longitudinal investigation into childhood- and adolescenceonset depression: psychiatric outcome in early adulthood. The British Journal of Psychiatry, 188, 216-222.

Ekers, D., Richards, D., \& Gilbody, S. (2008). A meta analysis of randomised trials of behavioural treatment of depression. Psychological medicine, 38, 611-623.

Lejuez, C. W., Hopko, D. R., \& Hopko, S. D. (2001). A brief behavioral activation treatment for depression: Treatment manual. Behavior Modification, 25, 255-286.

doi: $10.1177 / 0145445501252005$.

Lejuez, C. W., Hopko, D. R., Acierno, R., Daughters, S. B., \& Pagoto, S. L. (2011). Ten Year Revision of the Brief Behavioral Activation Treatment for Depression (BATD): Revised Treatment Manual (BATD-R). Behavior Modification, 35, 111-161. doi: 10.1177/0145445510390929.

Lewinsohn, P. M., Rohde, P., \& Seeley, J. R. (1998). Major depressive disorder in older adolescents: Prevalence, risk factors, and clinical implications. Clinical Psychology Review, 18, 765-794.

Martell, C. R., Addis, M. E., \& Jacobson, N. S. (2001). Depression in context: Strategies for guided action. New York: Norton. 
Manos, R. C., Kanter, J. W., \& Luo, W. (2011). The behavioural activation for depression scale-short form: development and validation. Behavior Therapy, 42, 726-739. doi: 10.1016/j.beth.2011.04.004.

McCauley, E., Gudmundsen, G., Schloredt, K., Martell, C., Rhew, I., Hubley, S., \& Dimidjian, S. (2015). The Adolescent Behavioral Activation Program: Adapting Behavioral Activation as a Treatment for Depression in Adolescence. Journal of Clinical Child \& Adolescent Psychology, doi: 10.1080/15374416.2014.979933.

McCauley, E., Schloredt, K., Gudmundsen, G., Martell, C., \& Dimidjian, S. (2011). Expanding Behavioral Activation to depressed adolescents: Lessons learned in treatment development. Cognitive and Behavioral Practice, 18, 371-383. doi:10.1016/j.cbpra.2010.07.006.

Miller S. D., Duncan B. L., (2000) The outcome rating scale. Author, Chicago.

NICE (2009). CG90 Depression in adults: The treatment and management of depression in adults (update). NICE clinical guideline 90, issued October 2009. https://www.nice.org.uk/guidance/cg90

NICE (2015). CG28 Depression in children and young people: Identification and management in primary, community and secondary care. NICE clinical guideline 28, issued September 2005. Updated March 2015. http://www.nice.org.uk/guidance/cg28

Polancyk, G., Salum, G., Sugaya, L., Caye, A., \& Rohde, L. (2015). Annual Research Review: A meta-analysis of the worldwide prevalence of mental disorders in children and adolescents. Journal of Child Psychology and Psychiatry 56, 345-365.

[Detail of Authors] (2014). Treatment manual for Brief Behavioural Activation for Depressed Adolescents (BATD-A). Unpublished manual, [location of authors]. [Details removed to ensure blind review]

Ritschel, L. A., Ramirez, C. L., Jones, M., Craighead, W. E. (2011). Behavioral Activation for Depressed Teens: A Pilot Study. Cognitive and Behavioral Practice, 18, 281-299. doi:10.1016/j.cbpra.2010.07.002.

Rudolph, K. D. \& Klein, D. N. (2009). Exploring depressive personality traits in youth: Origins, correlates, and developmental consequences. Development and Psychopathology, 21, 1155-1180. doi: 10.1017/S0954579409990095. 
Ruggiero, K. J., Morris, T. L., Hopko, D. R., \& Lejuez, C. W. (2005). Application of Behavioral Activation Treatment for Depression to an Adolescent with a History of Child Maltreatment. Clinical Case Studies, 2, 1-17. doi: 10.1177/1534650105275986.

Stallard, P., Udwin, O., Goddard, M., \& Hibbert, S. (2007). The Availability of Cognitive Behaviour Therapy Within Specialist Child and Adolescent Mental Health Services (CAMHS): A National Survey. Behavioural and Cognitive Psychotherapy, 2007, 35, 501-505. doi: 10.1017/S1352465807003724.

Thapar, A., Collishaw, S., Pine, D. S., \& Thapar, A. K. (2012). Depression in adolescence. Lancet, $379,1056-67$.

Vivyan, C. (2014) ACE log. Retrieved from http://www.getselfhelp.co.uk/freedownloads2.htm Weisz, J. R., McCarty, C. A., Valeri, S. M. (2006). Effects of psychotherapy for depression in children and adolescents: A meta-analysis. Psychological Bulletin, 132, 132-149. doi: 10.1037/00332909.132.1.132.

\section{Figure captions:}

Figure 1. Fiona's simplified behavioural maintenance formulation for low mood

Figure 2. Measures through the course of BATD-A 